Original Article

\title{
TOXICITY OF SPIROTETRAMAT ON SOLITARY BEE LARVAE, OSMIA CORNUTA (HYMENOPTERA: MEGACHILIDAE), IN LABORATORY CONDITIONS
}

\author{
Fabio Sgolastra ${ }^{1 *}$ \\ Simone Tosi ${ }^{1}$ \\ Piotr Medrzycki² \\ Claudio Porrini ${ }^{1}$ \\ Giovanni Burgio ${ }^{1}$ \\ 'Department of Agricultural Science, Alma Mater Studiorum University of Bologna, \\ viale Fanin 42, 40127 Bologna, Italy. \\ ${ }^{2}$ Agricultural Research Council, Honey Bee and Silkworm Research Unit, \\ via di Saliceto 80, 40128 Bologna, Italy. \\ *corresponding author: fabio.sgolastra2@unibo.it \\ Received 06 March 2015; accepted 07 October 2015
}

\begin{abstract}
A bstract
In this paper we assessed, under laboratory conditions, the toxicity of an active substance on solitary bee larvae of Osmia cornuta (Hymenoptera: Megachilidae). A field-realistic dose of the systemic insecticide spirotetramat was applied to the mass provisions. The insecticide's effects on several life-cycle parameters were studied in males and females. Our results showed a significantly shorter post-emergence longevity in bees exposed to spirotetramat during the larval stage, compared to the control. The observed reduction in longevity was 18 and 15\%, respectively, in males and females. Mortality rate and other biological traits (larval and spinning duration, emergence time, food/body conversion rate) did not show significant differences between the two treatments. The method described in this study can be used to test the effects of toxic substances (i.e. agrochemicals) on bees. Moreover, it can constitute a basis for the development of a standardised protocol in the first tier of the Environmental Risk Assessment for solitary bees.
\end{abstract}

Keywords: bee, ecotoxicology, insecticide, pesticide, toxicity test.

\section{INTRODUCTION}

Bees provide important ecological functions, sustaining basic ecosystem services and human food production (Klein et al., 2007; Gallai et al., 2009; Brittain and Potts, 2011). Besides honey bees (Apis mellifera L.) and bumblebees (Bombus Spp.), many species of managed and wild solitary bees offer an important pollination service and their contribution has been recently pointed out (Garibaldi et al., 2013). For these reasons the protection of bees, as a functional group of pollinators, was addressed in the Environmental Risk Assessment (ERA) of Plant Protection Products (PPPs) and of Genetically Modified Organisms (GMOs) (European Commission, 2009).

Recently, the European Food Safety Authority (EFSA) has published the Guidance Document (GD) on the risk assessment of PPPs on bees, including honey bees, bumblebees, and solitary bees (EFSA, 2013). The aim of this GD is to outline a process by which PPPs can be evaluated for their potential risks to bees and how PPPs can be evaluated for providing the same level of protection for the three bee groups. Up till now, only the honey bee has been considered in the regulatory process of the PPPs, and there is no validated test protocol available for non-Apis bees. A recent meta-analysis comparing the sensitivity of bees to pesticides, highlighted the need to extend the risk assessment of PPPs to other bee groups, and to include other species in the test (Arena and Sgolastra, 2014). In order to introduce a new test organism in the regulatory risk assessment of PPPs and GMOs, a species should: 1) be reared and easily managed in order to obtain a large population, 2) be economically and ecologically important, and 3) show several behavioral and life cycle traits representative of many species of 
the same taxonomic or ecological group. The mason bees (Osmia spp.) show all the above traits, making these bees good candidates for this purpose. In fact, several Osmia species are currently reared and managed as crop pollinators in Europe, the US, and Asia (Bosch and Kemp, 2002). The developmental biology of the mason bees is well known and appropriate rearing methods and management systems have been established (Bosch et al., 2008).

All species of the genus Osmia are solitary bees (Hymenoptera, Megachilidae) with a Holarctic distribution. Most of these species are univoltine and spend the winter as cocooned adults. Because most Osmia fly early in the year, they have been used in different parts of the world to pollinate springblooming crops. In Japan, Osmia cornifrons (Radoszkowski) has been used as an apple pollinator since the 1960s. The sister species, Osmia lignaria Say, is reared and commercialised in North America to pollinate apple, cherry, and almond flowers. In Europe, two other species, Osmia rufa (L.) (syn. Osmia bicornis L.) and Osmia cornuta (Latr.), have been used as pollinators in several fruit crops (apple, pear, almond) and in caged Brassicaceae for seed production (Bosch et al., 2008). Species of the genus Osmia have already been used in ecotoxicological studies and some protocols are available in literature (e.g. Ladurner et al., 2005; Abbott et al., 2008; Konrad et al., 2008; Sandrock et al., 2014). Nonetheless, these protocols need to be ring-tested to validate their reliability, repeatability, and reproducibility.

Osmia cornuta is a Palearctic mason bee found in central and southern Europe, Turkey, and parts of North Africa and the Middle East (Peters, 1977). The adult insects, which show proterandry, emerge from the cocoons and fly in early spring. After mating, females start nesting in pre-established cavities. In the cavities, the females build a series of cells separated with mud partitions (Bosch et al., 2008). Each cell is provided with a mass of pollen and nectar, on top of which an egg is deposited. In each nest, the cells that are closer to the bottom of the cavity are larger and are occupied by female offspring (diploid eggs) whereas the cells that are in the proximity of the nest exit, are smaller and are occupied by male offspring (haploid eggs). One nesting female is active for about 3 weeks. By mid-summer (about 1 - 1.5 months from egg hatching), fifth-instar (larva) bees have completely consumed the pollennectar provision, defecated, and spinned a cocoon with silk-like strands. At this stage, under field conditions, bees enter in a prepupal summer diapause for $~ 1$ month (Sgolastra et al., 2012). In late summer, the insects complete their development and the adults eclose within the cocoon. They remain inside their cocoons in a dormant stage (diapause) throughout the winter period and they emerge in the spring as temperatures increase (Bosch et al., 2008).

Osmia spp. can be affected by exposure to pesticides in the agricultural environments. A recent field study showed that Osmia populations could be even more affected than honey bees and bumblebees (Rundlöf et al., 2015).

Spirotetramat is a new systemic insecticide belonging to the class of tetramic acid derivatives. It is used against several sucking pests, such as aphids, psyllids, scales, mealy bugs, and whiteflies. Its mode of action is based on the inhibition of the lipid biosynthesis. This chemical compound has been developed to be used worldwide on a vast variety of crops such as pome fruits, stone fruits, citrus, grapes, almonds, nuts, hops, tea, vegetables, cotton, and tropical fruits (Maus, 2008). Analyses of pesticide residues in citrus blossoms have shown spirotetramat concentrations of 0.36 - 3.54 ppm, after the application of the commercial product (Movento ${ }^{\circledR}$ ) at the maximum label rate for citrus (i.e., $175 \mathrm{~g}$ of active substance per ha). The maximum residue level was 0.04 and $0.32 \mathrm{ppm}$, respectively, for nectar and for pollen collected from flowers (Rogers et al., 2010). Acute toxicity tests on honey bees showed that spirotetramat can be considered safe for $A$. mellifera $\left(\mathrm{LD}_{50}\right.$ oral $=107.3 \mu \mathrm{g}$ active substance (a.s.)/bee; $\mathrm{LD}_{50}$ contact $>100.0 \mu \mathrm{g}$ a.s./bee). However, this compound could affect bee brood artificially exposed to sugar solutions which contain $0.0144 \%$ of test substance (144 mg a.s./L) (Maus, 2008). Although no adverse effects on brood development and other endpoints were observed when higher-tier studies were carried out on honey bees (Maus, 2008), detrimental effects of spirotetramat on the larvae of Osmia cannot be excluded. Compared with the larvae of $A$. mellifera, non-Apis bee larvae may be more exposed to pesticide residues in the pollen (Babendreier et al., 2004; Schindler et al., 2013). Honey bee larvae are mainly fed with glandular secretions from adult bees and ingest only very small amounts of unprocessed pollen, whereas larvae of solitary bees consume high amounts of the latter which constitutes the main part of their diet. For example, the pollen consumption of 0 . cornuta females and honey bee workers during the larval stage is, on average, 387 and $1.5-2 \mathrm{mg}$, respectively (EFSA, 2013). This means that the potential pesticide exposure via 
pollen is for 0 . cornuta, about 200 - 260 times higher than for $A$. mellifera larvae. At the moment, there are no available studies dealing with the effects of spirotetramat on Osmia spp.

Some methods for toxicological tests of different xenobiotics on Osmia larvae have been published, but the techniques have not been standardised yet (Tesoriero et al., 2003; Konrad et al., 2008; Abbott et al., 2008). Tesoriero et al. (2003) tested 0 . cornuta for toxicity of two fungicides (kresoximmethyl and copper oxychloride) and one insecticide (Quassia amara extract) at field doses, by applying $1 \mu \mathrm{L}$-drop of the test solution in the centre of the upper surface of the provisions. Konrad et al. (2008) studied the effects of three insecticidal proteins (rOC-1, GNA and Cry1Ab), that are expressed in genetically modified plants, on 0 . rufa larvae. The insecticidal proteins used by Konrad et al. (2008) were dissolved in water and spiked in the mass provisions achieving the final concentrations of 0.01 and $0.1 \%$ of fresh pollen provision (w/w). Abbott et al. (2008) tested the lethal and sublethal effects of imidacloprid at four concentrations $(0,3,30$, and $300 \mathrm{ppb}$ ) in larvae of 0 . lignaria. Two different laboratory methodologies were used to apply the test solution in the mass provision. In the first method ("own pollen"), $10 \mu \mathrm{L}$ of the four varying pesticide concentrations was injected in the pollen provisions by using a $50-\mu \mathrm{L}$ Hamilton syringe attached to a Hamilton PB600-1 dispenser. In the second method ("new pollen"), the pollen provision was replaced with a pre-blended pollen mixture containing the appropriate amounts of imidacloprid. Our study deals with the potential effects of spirotetramat consumed by 0 . cornuta during larval development. In our study, we decided to apply the test solution without removing the attached egg. This was done to avoid or minimise the manipulation of the provision. We performed the experiment with spirotetramat aqueous solution applied in a longitudinal hole previously formed in the provision, similar to the study performed by Konrad et al. (2008), obtaining the estimated average concentration of $1.4 \mathrm{ppm}$ in the provision. The tested concentration can be considered ecologically relevant because it is included within the range of the residue concentrations detected in the flowers of the crop treated with this compound (Rogers et al., 2010).

The aim of our study was to assess the effects of spirotetramat on 0 . cornuta males and females, during development and after emergence, under laboratory conditions. Our results are discussed in order to provide some scientific base so a general standard laboratory test protocol can be developed. The effects of toxicants (including pesticides and insecticide proteins expressed in the pollen of transgenic plants) in solitary bees, would be assessed in the framework of the Environmental Risk Assessment.

\section{MATERIAL AND METHODS}

\section{Bee population}

Bees were obtained from a population of 0 . cornuta nested near Bologna (Italy) in a 7-hectare field of organic oilseed rape. There were no other flowering crops in the surroundings during the nesting period. In mid-April 2012, during oilseed rape flowering, $\sim 700$ females and 1400 males were released as loose cocoons into a cardboard box. There were holes in the box through which the bees could fly out. The box was positioned in the proximity of a nesting shelter, in the middle of the field. The nesting shelter consisted of three wooden blocks with 144 drilled holes per block. Each hole was $15 \mathrm{~cm}$ long and equipped with an $8 \mathrm{~mm}$ inside-diameter paper straw. The nests were checked in the middle of the nesting period, and newly-plugged paper straws (completed nests) were pulled out of the wooden block and taken to the laboratory.

\section{Rearing method and pesticide application}

In mid-May, terminated nests were dissected and the provisions with eggs and first instar larvae (those remaining inside chorion) were individually weighed and placed in 48-well culture plates. The eggs/larvae with provisions were sexed, based on the provision size and cell position within the nest, and randomly assigned to the treatments. Females are located deeper in the nest and are provided with larger provisions (Bosch et al., 2008). Since each nest is usually provisioned by a single female, to account for genetic similarities, egg or larva for each sex was distributed among treatments. This was done so that no treatment received more than one individual from the same nest. The sex was confirmed after emergence of the bees from the cocoons. The eggs/ larvae were dated considering that the nest was dissected the day after its termination and assuming a cell production rate of 1 cell/day (Bosch and Vicens, 2005; 2006). All the provisions were contaminated with the pesticide the same day as the nest dissections. We assumed no effect of the bee age on the exposure level because the first instar larva remains inside the egg's spilt chorion and feeds only on egg fluids, until it reaches the second instar. 


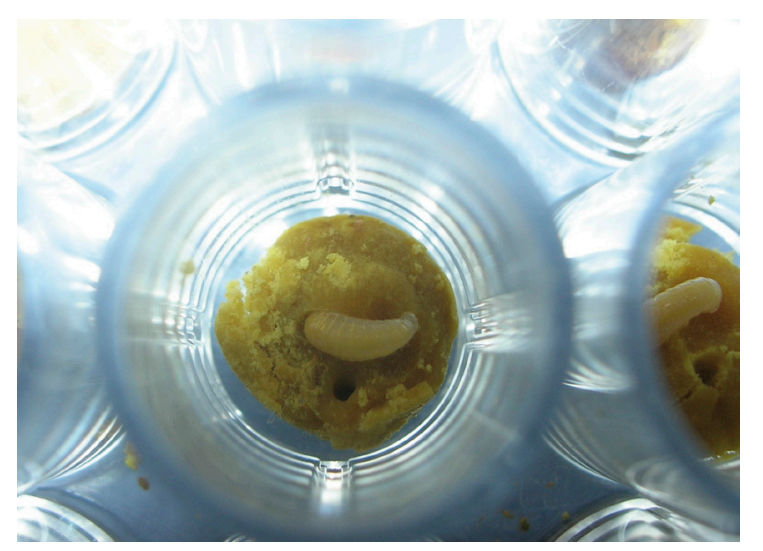

Fig. 1. Provision with Osmia cornuta larvae individually placed in 48-well culture plates. Note the longitudinal hole where the test solution was applied.

The pesticide stock solution was prepared dissolving $1.1 \mathrm{mg}$ of spirotetramat in $1 \mathrm{~mL}$ of acetone. The test solution was obtained by mixing $0.65 \mathrm{~mL}$ of stock solution in $10 \mathrm{~mL}$ of distilled water. The control and treated test solution contained water with $6.5 \%$ of acetone only. The test solution was distributed within the pollen provision, without removing the attached egg, into a longitudinal hole previously made using a needle (Fig. 1). Ten and $5 \mu$ of test solution were added to female and male provisions, respectively. Each provision contained an estimated average concentration of $~ 1.4 \mathrm{ppm}$ of spirotetramat ( $\mu$ g of active substance/g of mass provision), when considering 0.5 and 0.25 g to be the average fresh weight of the provision mass (Bosch and Vicens, 2002). Therefore, the acetone amount added to each provision was $<1 \%(\mathrm{w} / \mathrm{w})$. The actual doses of spirotetramat consumed were 0.72 and $0.36 \mu \mathrm{g}$ per each female and male provision, respectively. Sample sizes were 22 males and 12 - 13 females per each treatment (a total of 44 males and 25 females). The eggs/larvae were maintained in culture plates placed in an incubator at $23 \pm 1^{\circ} \mathrm{C}$ and $55-65 \% \mathrm{RH}$ (no light). Their development was observed daily until cocoon spinning (mid June). On 24 September, when all individuals had reached the adult stage, bees (in their cocoons) were transferred to $12^{\circ} \mathrm{C}$ for one week, and then to $2^{\circ} \mathrm{C}$ for a wintering period of 180 days. After wintering, the bees inside the cocoons were individually transferred on 2 April 2013, from the culture plates to transparent cylindric polystyrene cages (diameter $5.5 \mathrm{~cm}$, height $3.5 \mathrm{~cm}$ ) and incubated at $24 \pm 1^{\circ} \mathrm{C}$. Bees were checked daily to assess the date of emergence from the cocoon, and the longevity.

\section{Data collection}

The following end-points were recorded during the experiment:

- mortality rate: number of bees dead during larval development (from egg/larva to adult) and wintering (before emergence);

- larval period: number of days from eggs/first instar larvae to beginning of the cocoon spinning;

- spinning duration: number of days from the beginning of the cocoon spinning to the cocoon completion;

- emergence time: number of days required to emerge after the beginning of the incubation at $24^{\circ} \mathrm{C}$;

- post-emergence longevity: number of days the bee lived after emergence. The longevity of the bees after emergence without feeding was used to measure the remaining energy reserves and consequently to estimate the vigour of the bees (Bosch and Kemp, 2000);

- food/body conversion rate: the percentages of adult body weight were calculated before and after wintering in reference of the initial investment weight (egg + provision). Adult bees were weighed within their cocoons, without faecal particles, before and after wintering. Cocoon weight was measured at the end of the study and subtracted from the previous weight measurements.

\section{Statistical analysis}

Mortality rate differences between the control and treated bees were analysed with a Chi-square test. Males and females were analysed separately. Feeding period, cocooning duration, emergence time, and post-emergence longevity were analysed using two-way ANOVA to evaluate differences among treatments and sexes. Because the same male and female individuals were weighed throughout their 
life cycle, a two way repeated-measures ANOVA was used to analyse percent weight data (arcsinetransformed), with sex as the between-subjects factor and season (before and after wintering) as the within-subjects factor. All statistical analyses were carried out using Statistica version 7 software.

\section{RESULTS}

Mortality rate was not affected by the treatment in males $\left(\chi^{2}=0.61, \mathrm{df}=1, \mathrm{p}=0.43\right.$ ) or in females $\left(\chi^{2}=0.16, \mathrm{df}=1, \mathrm{p}=0.69\right)$. In total, only 8 males (13.6\% in the control and $22.7 \%$ in the treated) and 5 females $(23.1 \%$ in the control and $16.7 \%$ in the treated) died during larval development and wintering.

On the average, Osmia cornuta larvae needed about 1 month to consume all the provisions when they were reared at $23^{\circ} \mathrm{C}$. It took the males approximately 4 days to complete the spinning of their cocoons (Fig. 2 and 3). Larval period and spinning duration were not significantly affected by the treatment.

However, females spent more time to complete the spinning of their cocoons. No significant treatmentsex interaction was found (Tab. 1; Fig. 2 and 3). Emergence time was not affected by the treatment, but, females generally required more time to emerge from the cocoons (Tab. 1; Fig. 4).

When bees were checked for emergence (Spring 2013), four individuals ( 2 in the control group and 2 in the treated group) remained in the prepupal stage (summer prepupal diapause). These data were established by checking inside the cocoon through a slit cut with a razor blade at the apical tip of the cocoon. These individuals were alive and had a healthy appearance.

The post-emergence longevity of the bees exposed to the pesticide during their larval development was significantly shorter than the control bees. Males lived significantly longer than females. No significant treatment-sex interaction was observed (Tab. 1; Fig. 5).

Treatment and sex did not affect the food/body conversion rate. However, the season (before or

Table 1.

Results of two-way ANOVA of the: larval period, spinning duration, emergence time, and post-emergence longevity in relation to the treatment and sex. Significant differences are denoted with * after $p$-value $(p<0.05)$

\begin{tabular}{|c|c|c|c|c|c|c|c|c|c|c|c|c|}
\hline & \multicolumn{3}{|c|}{ Larval period } & \multicolumn{3}{|c|}{ Spinning duration } & \multicolumn{3}{|c|}{ Emergence time } & \multicolumn{3}{|c|}{$\begin{array}{c}\text { Post-emergence } \\
\text { longevity }\end{array}$} \\
\hline & $\mathrm{F}$ & df & $p$ & $\mathrm{~F}$ & $d f$ & $P$ & $\mathrm{~F}$ & $\mathrm{df}$ & $p$ & $\mathrm{~F}$ & df & $\mathrm{p}$ \\
\hline Treat & 0.004 & 1,48 & 0.95 & 0.05 & 1,51 & 0.83 & 1.25 & 1,47 & 0.27 & 5.85 & 1,46 & $0.02^{\star}$ \\
\hline Sex & 1.54 & 1,48 & 0.22 & 4.85 & 1,51 & $0.03^{\star}$ & 12.52 & 1,47 & $<0.01^{*}$ & 4.82 & 1,46 & $0.03^{*}$ \\
\hline $\begin{array}{l}\text { Treatment } x \\
\text { Sex }\end{array}$ & 0.65 & 1,48 & 0.42 & 0.46 & 1,51 & 0.50 & 0.15 & 1,47 & 0.70 & 0.23 & 1,46 & 0.64 \\
\hline
\end{tabular}

Table 2.

Results of ANOVA of the food/body conversion rate in relation to the treatment, sex, and season (before and after wintering). Significant differences are denoted with * after $p$-value $(p<0.05)$

\begin{tabular}{lccc}
\hline & \multicolumn{3}{c}{ Food weight/body weight } \\
& $\mathrm{F}$ & $\mathrm{df}$ & $\mathrm{P}$ \\
\cline { 2 - 4 } & 1.40 & 1,48 & 0.24 \\
Treatment & 3.36 & 1,48 & 0.07 \\
Sex & 0.59 & 1,48 & 0.44 \\
Treatment x Sex & 250.15 & 1,48 & $<0.01^{\star}$ \\
Season & 0.04 & 1,48 & 0.83 \\
Season x Treatment & 0.77 & 1,48 & 0.38 \\
Season x Sex & 1.40 & 1,48 & 0.24 \\
Season x Treatment x Sex & & &
\end{tabular}




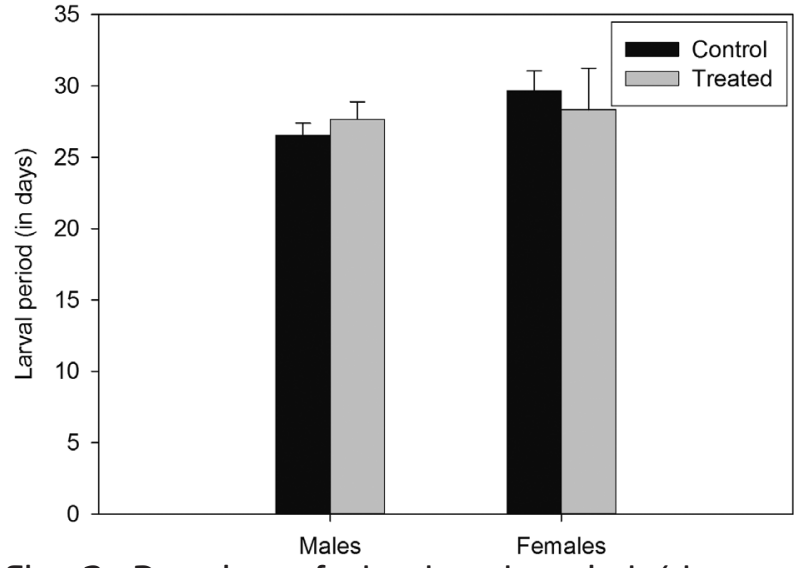

Fig. 2. Duration of the larval period (the mean and SE) in Osmia cornuta males and females exposed to spirotetramat (treated) and water (the control).

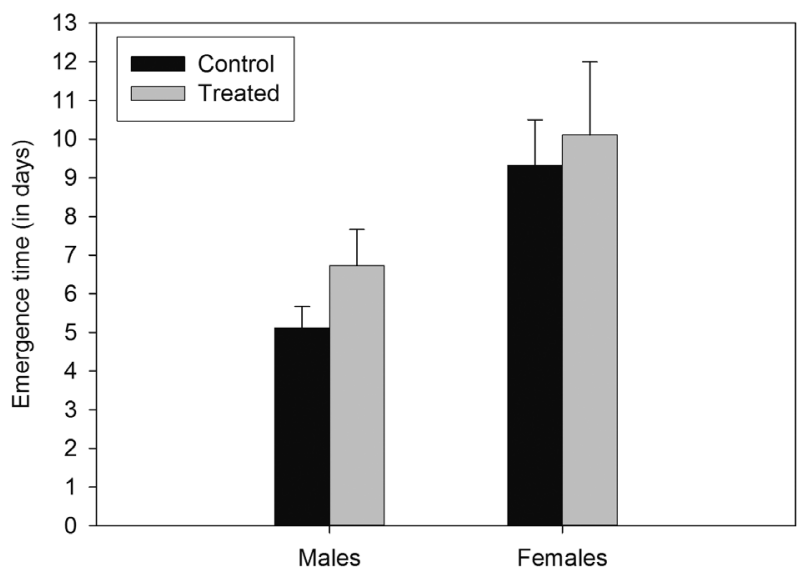

Fig. 4. Duration of the emergence time (the mean and SE) in Osmia cornuta males and females exposed to spirotetramat (treated) and water (the control).

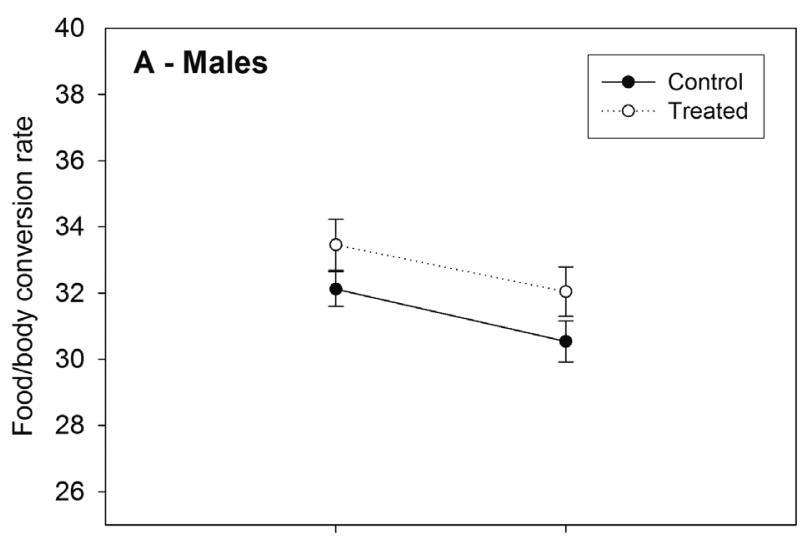

A. 24 September

2 April

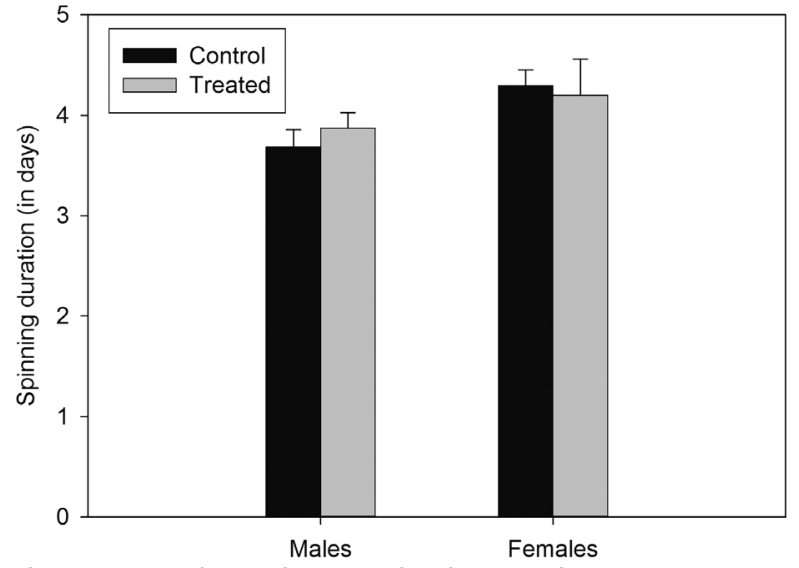

Fig. 3. Duration of the spinning period (mean and SE) in Osmia cornuta males and females exposed to spirotetramat (treated) and water (the control).

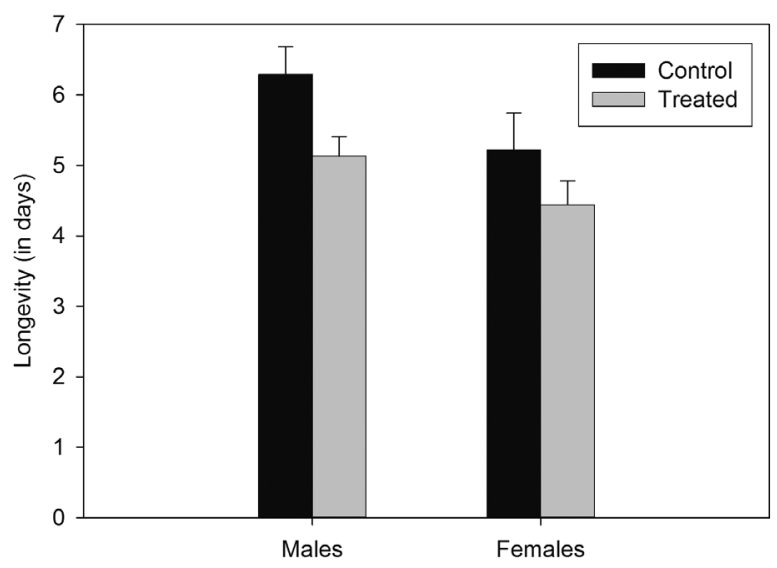

Fig. 5. Duration of the post-emergence longevity (the mean and SE) in Osmia cornuta males and females exposed to spirotetramat (treated) and water (the control).

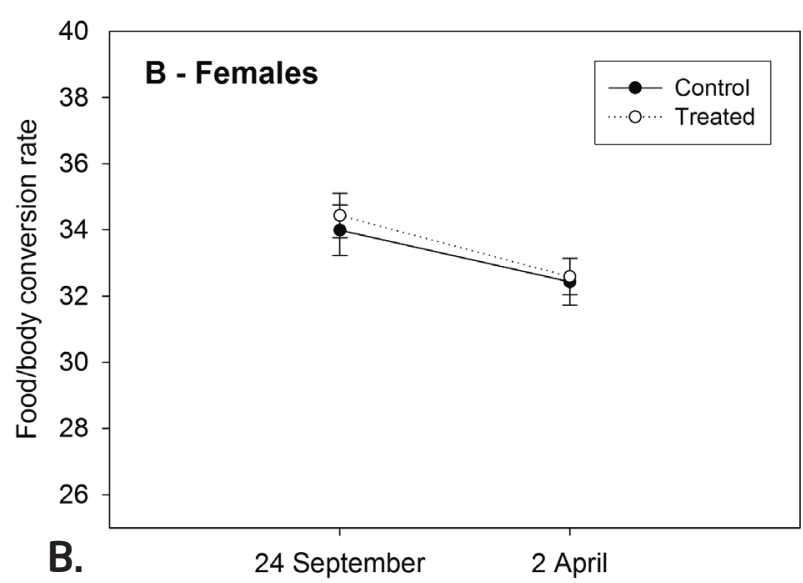

Fig. 6. Food/body conversion rates in males $(A)$ and females $(B)$ expressed as the percentages (the mean and SE) of adult body weight calculated on 24 September and 2 April (before and after wintering) in reference of the initial investment weight (provision + egg). 
after wintering) significantly affected the adult body weight variations (Tab. 2). Before wintering, on average, male body weight was $32.8 \%$ of the initial investment weight, while female body weight was $34.2 \%$. After wintering, these values were lower 31.3 and $32.5 \%$, respectively. Any significant second or third level interactions among treatments, sex, and season were observed (Tab. 2; Fig. 6).

\section{DISCUSSION}

In this study we contaminated the provisions with $\sim 1.4 \mathrm{ppm}$ of spirotetramat (0.72 and $0.36 \mu$ g of active substance - a.s.-per female and male provision, respectively) and we assessed the effects on larval development and post-emergence longevity of the solitary bees, 0 . cornuta. These doses correspond to the actual exposure levels since the pollen provision was entirely consumed by all bees. Moreover, the pesticide concentration can be considered ecologically relevant because it was within the range of the residues (0.36 - $3.54 \mathrm{ppm})$ found in the blossom of the treated citrus crop at the maximum label rate (175 g a.s./ha). If we independently consider the residues in nectar and pollen (0.04 and 0.32 ppm, respectively), though, the tested concentrations were higher. In field conditions, we predict a higher exposure to spirotetramat on Osmia spp. than honey bee or bumblebee larvae, due to the large pollen consumption of solitary bee larvae (EFSA, 2013). An intrinsic brood-damaging potential of spirotetramat in the larvae of $A$. mellifera has already been showed by Maus (2008). In 2013, a bee mortality event, probably linked to spirotetramat application to orange trees, was observed in Southern Italy (data from BeeNet project: www.reterurale. it/api). Chemical analysis showed residues of this compound in both orange leaves (122 ppb, collected in the crop surrounding the apiary) and dead bees (0.26 ppb, collected in the damaged hives) (data from BeeNet project: www.reterurale.it/api). In our study, the larvae exposed to spirotetramat did not show a significant increase in the mortality rate of the larvae during development. No effects were observed in development duration, emergence time, or food/body conversion rate. A significant effect on post-emergence longevity, though, was found. Adult bees which were exposed to spirotetramat during the larval stage lived shorter than unexposed bees (18 and 15\% of reduction in longevity, respectively, in males and females). These results suggest that spirotetramat decreases the vigour of bees after emergence, negatively affecting the energetic budget accumulated during larval feeding. In fact, spirotetramat acts as lipid biosynthesis inhibitor (Maus, 2008). Lipid reserves accumulated during larval development are very important in Osmia spp., and depletion of the reserves affects both the wintering survival and the vigour of the bees after emergence (Sgolastra et al., 2011; Wasielewski et al., 2013). Because the difference in adult longevity between treated and control bees, was an average of 1 day, further studies are necessary to assess whether the observed effect is relevant in field conditions. It should be noted, that at the population level, a reproductive decline cannot be excluded because longevity and fecundity are related in Osmia nesting females (Bosch and Vicens, 2006).

Our laboratory method could be suitable to test the toxicity of xenobiotics in larvae of solitary bees of the genus Osmia. But, the development of a test protocol to be used in ERA needs a standardisation of four major issues: 1) the rearing methods of the test species; 2) the conditions during the test; 3 ) the mode of pesticide application; 4) the identification and the measurement of the endpoints.

The sum of development mortality (rate of bees that do not reach the adult stage) and wintering mortality (rate of bees that died during wintering) of Osmia bees living in undisturbed and adequate conditions, should not be higher than 10\% (Bosch and Kemp, 2001). Excluding parasites and pathogens, the main factors that affect Osmia survival are: the development, the pre-wintering, and the wintering conditions (Bosch et al., 2008). In our study, the overall mean mortality (development and wintering) rate was 18.8\% and there were no significant differences between the treated and the control group. Because most mortality occurred during the first larval stages, the manipulation may have been the main factor that influenced the mortality rate. Since a certain level of manipulation is inevitable in toxicological studies, a mortality of around $15 \%$ can still be considered acceptable as recommended for the artificial rearing of honey bee larvae (Crailsheim et al., 2012). In other studies with Osmia larvae, the control mortality was only slightly lower than our data: $13 \%$ (development + wintering mortality) in O. bicornis (Konrad et al., 2008), 10\% (only development mortality) in 0. cornuta (Tesoriero et al., 2003). What is more, in our study, the longevity of the untreated bees which had emerged in spring was within the range of the life span of the bees reared under optimal conditions (Bosch and Kemp, 2004). This suggests that the rearing conditions used in our study can be considered suitable. However, the test temperature during development $\left(23^{\circ} \mathrm{C}\right)$ might not 


\section{_ SGULASTHA Et HL.___ Toxicity of spirotetramat on solitary bee larvae}

have been high enough for some individuals of this 0 . cornuta population to have been able to complete prepupal development. In fact, the prepupal period in Osmia corresponds to a summer diapause which requires fluctuating temperatures or, depending on the geographic origin of the population, warmer temperatures to complete its development (Radmacher and Strohm, 2011; Sgolastra et al., 2012). Similar percentages of prolonged prepupal dormancy were also observed in a late flying population of 0 . cornuta reared at $22^{\circ} \mathrm{C}$. These bees can remain in the prepupal stage for more than one year without any apparent difference, but they can then resume their development when exposed to warmer temperatures (Sgolastra et al., 2012). On the other hand, the larval mortality increases at higher temperatures (Bosch and Kemp, 2000; Radmacher and Strohm, 2010). For these reasons, the optimal test temperature should be between $24^{\circ} \mathrm{C}$ and $26^{\circ} \mathrm{C}$. Another critical point for the Osmia spp. rearing is the well dimension of the culture plates. The 48-well $(9.8 \mathrm{~mm})$ culture plates used in our study were suitable for 0 . cornuta rearing, while the 24-well culture plates $(15.5 \mathrm{~mm})$ were too large for the appropriate cocoon construction. Too large of a size causes cocoon failure (Abbott et al., 2008).

An important issue in the development of the toxicity test method for larvae of solitary bees in laboratory conditions is the mode of administration of the test compound. Up to now, the methods described in literature can be divided into two groups: 1) contamination of the bee's own pollen provision by applying the entire test solution to a localised spot of the provision and, possibly, without removing the attached egg or 2) replacing the pollen provision with a pre-blended pollen mixture containing the appropriate amount of test product in relation to the provision weight. The former method was applied by Tasei et al. (1988), Peach et al. (1995), Abbott et al. (2008), Huntzinger et al. (2008), Hodgson et al. (2011), Gradish et al. (2012) for studies on Megachile rotundata, and by Tesoriero et al. (2003), Abbott et al. (2008), Konrad et al. (2008) on Osmia spp. The latter method, as already mentioned, was applied only by Abbott et al. (2008). Although this method ensures a more homogeneous contamination of the pollen provision, we believe that the former one should be preferred due to the high mortality rate observed when larvae were fed on manipulated provisions (man-made mixture of pollen and nectar) (Abbott et al., 2008). We recognise that there are some limitations in the first method, because the entire dose can be ingested by the larvae in a short period of time. This action reproduces a situation of acute, rather than chronic, exposure. Also, different larvae may ingest the dose at different developmental stages. This action leads to differences in their susceptibility, increasing the amount of background variability among tested individuals. Provisions may differ in size, pollen composition, and in the levels of pesticide residues, if any, again increasing the background variability among tested individuals. This latter point can be overcome by doing what we did in our study, that is, by releasing the bees in a large organic field attractive to the test species and using uniform nesting materials. Most Osmia cornuta females nest within 100 - $200 \mathrm{~m}$ from their nests (Vicens and Bosch, 2000). In order to resolve the first two points, further research is necessary to allow a uniform distribution of the pesticide within the provision mass without affecting bee survival. In ecotoxicological studies, the choice of which endpoints to evaluate is another important issue. These endpoints should predict the potential effects on bee populations in the field, when bees are exposed to pesticides or other contaminants. Some sub-lethal effects have been taken into account in a semi-field study with 0 . lignaria. The effects taken into account included foraging time, cell production rate, and fecundity (Ladurner et al., 2008). Previous studies showed that longevity, the fat body depletion, and the body weight and fecundity are all interconnected (Bosch and Kemp, 2004; Bosch and Vicens, 2005; 2006; Bosch et al., 2010). Thus, the longevity of bees after emergence in laboratory conditions could be considered a good indicator of the vigour of the bees in field. A potential biomarker which is useful to detect potential stressors early during the development in solitary bees, might be the study of anti-oxidative system (Dmochowska et al., 2012). To our knowledge, though, no ecotoxicological study dealing with solitary bees and pesticides is available on this topic.

\section{CONCLUSIONS}

In conclusion, we showed that field realistic doses of spirotetramat, an insecticide commonly used on several fruit crops, can affect the quality of 0 . cornuta in laboratory conditions. In fact, the consumption of pollen provisions contaminated with an average of $1.4 \mathrm{ppm}$ of spirotetramat, reduce the post-emergence longevity of adults. Further higher tier studies are still necessary to assess the ecological relevance of this effect. An assessment is particularly needed if spirotetramat affects repro- 
duction, i.e. whether the progeny production is lower in females exposed to this insecticide during the larval stage. Moreover, the test method described in this study can constitute a basis for the development of a standardised protocol in the first tier of the ERA for solitary bees. This method can be used to test both systemic pesticides and other xenobiotic compounds, such as toxins expressed in transgenic plants, heavy metals, and other pollutants.

\section{ACKNOWLEDGMENTS}

We thank Stephan Härtel, Karin Steijven (University of Würzburg), and two anonymous reviewers for the useful comments that improved the manuscript. We are indebted to Enrico Muzzi (University of Bologna) for his valuable suggestions concerning the appropriate statistical analysis. This is the publication No. 11 produced within the framework of the project Assessing and Monitoring the Impacts of Genetically Modified Plants on Agro-Ecosystems (AMIGA), funded by the European Commission in the Framework programme 7. THEME [KBBE.2011.3.501].

\section{REFERENCES}

Abbott V. A., Nadeau J. L., Higo H. A., Winston M. L. (2008) Lethal and sublethal effects of imidacloprid on Osmia lignaria and clothianidin on Megachile rotundata (Hymenoptera: megachilidae). Journal of Economic Entomology 101: 784-796.

Arena M., Sgolastra F. (2014) A meta-analysis comparing the sensitivity of bees to pesticides. Ecotoxicology 23: 324-334.

Babendreier D., Kalberer N., Romeis J., Fluri P., Bigler $F$. (2004) Pollen consumption in honey bee larvae: a step forward in the risk assessment of transgenic plants. Apidologie 35: 293-300.

Bosch J., Kemp W. P. (2000) Development and emergence of the orchard pollinator, Osmia lignaria (Hymenoptera, Megachilidae). Environmental Entomology 29: 8-13.

Bosch J., Kemp W. P. (2001) How to manage the blue orchard bee as an orchard pollinator. Sustainable Agricultural Network. Beltsville, Maryland. 98 pp.

Bosch J., Kemp W. P. (2002) Developing and establishing bee species as crop pollinators: the example of Osmia spp. (Hymenoptera: Megachilidae) and fruit trees. Bulletin of Entomological Research 92: 3-16.
Bosch J., Kemp W. P. (2004) Effect of pre-wintering and wintering temperature regimes on weight loss, survival, and emergence time in the mason bee Osmia cornuta (Hymenptera: Megachilidae). Apidologie 35: 469-479.

Bosch J., Vicens N. (2002) Body size as an estimator of production costs in a solitary bee. Ecological Entomology 27: 129-137.

Bosch J., Vicens N. (2005) Sex allocation in the solitary bee Osmia cornuta: do females behave in agreement with Fisher's theory? Behavioral Ecology and Sociobiology 59: 124-132.

Bosch J., Vicens N. (2006) Relationship between body size, provisioning rate, longevity and reproductive success in females of the solitary bee Osmia cornuta. Behavioral Ecology and Sociobiology 60: 26-33.

Bosch J., Sgolastra F., Kemp W. P. (2008) Life Cycle Ecophysiology of Osmia Mason Bees Used as Crop Pollinators. In: James R. R., Pitts-Singer T. L. (Eds.) Bee Pollination in Agricultural Ecosystems. Oxford University Press. Oxford, UK: 83-104.

Bosch J., Sgolastra F., Kemp W. P. (2010) Timing of eclosion affects diapause development, fat body consumption and longevity in Osmia lignaria, a univoltine, adultwintering solitary bee. Journal of Insect Physiology 56: 1949-1957.

Brittain C., Potts S. G. (2011) The potential impacts of insecticides on the life-history traits of bees and the consequences for pollination. Basic and Applied Ecology 12: 321-331.

Crailsheim K., Brodschneider R., Aupinel P., Behrens D., Genersch E., Vollmann J., Riessberger-Gallé U. (2012) Standard methods for artificial rearing of Apis mellifera larvae. Journal of Apicultural Research 52: 1-15.

Dmochowska K., Giejdasz K., Fliszkiewicz M., Żółtowska K. (2012) Changes in antioxidative system of red mason bee (Osmia rufa) (Hymenoptera: Megachilidae) induced by artificially elongated postdiapause. Journal of Apicultural Science 56: 99-106.

EFSA (2013) EFSA Guidance Document on the risk assessment of plant protection products on bees (Apis mellifera, Bombus spp. and solitary bees). EFSA Journal $11(7): 3295.266$ pp. 


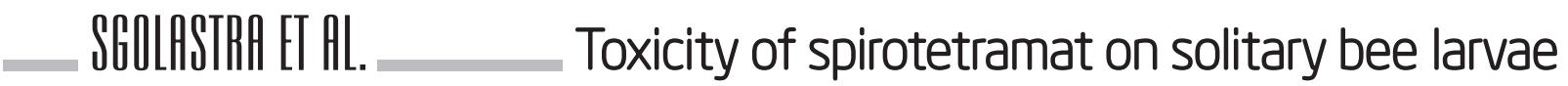

European Commissiom (2009) Regulation EC No 1107/2009 of the European Parliament and of the Council. Official Journal of European Union 309: 1-50.

Gallai N., Salles J. M., Settele J., Vaissiere B. E. (2009) Economic valuation of the vulnerability of world agriculture confronted with pollinator decline. Ecological Economics 68: 810-821.

Garibaldi L. A., Steffan-Dewenter I., Winfree R., Aizen M. A., Bommarco R., Cunningham S. A., Kremen C., Carvalheiro L. G., Harder L. D., Afik O., Bartomeus I., Benjamin F., Boreux V., Cariveau D., Chacoff N. P., Dudenhoffer J. H., Freitas B. M., Ghazoul J., Greenleaf S., Hipolito J., Holzschuh A., Howlett B., Isaacs R., Javorek S. K., Kennedy C. M., Krewenka K. M., Krishnan S., Mandelik Y., Mayfield M. M., Motzke I., Munyuli T., Nault B. A., Otieno M., Petersen J., Pisanty G., Potts S. G., Rader R., Ricketts T. H., Rundlof M., Seymour C. L., Schuepp C., Szentgyorgyi H., Taki H., Tscharntke T., Vergara C. $H_{\text {., }}$ Viana B. F., Wanger T. C., Westphal C., Williams N., Klein A. M. (2013) Wild pollinators enhance fruit set of crops regardless of honey bee abundance. Science 339: 16081611.

Gradish A. E., Scott-Dupree C. D., Cutler G. C. (2012). Susceptibility of Megachile rotundata to insecticides used in wild blueberry production in Atlantic Canada. Journal of Pest Science 85: 133-140.

Hodgson E. W., Pitts-Singer T. L., Barbour J. D. (2011) Effects of the insect growth regulator, novaluron on immature alfalfa leafcutting bees, Megachile rotundata. Journal of Insect Science 11: 43. Available at: http://lib.drilastate.edu/cgi/viewcontent. cgi?article $=1050 \&$ context $=$ ent_pubs

Huntzinger C. I., James R. R., Bosch J., Kemp W. P. (2008) Laboratory biossays to evaluate fungicides for chalkbrood control in larvae of the alfalfa leafcutting bee (Hymenoptera; Megachilidae). Journal of Economic Entomology 101:660-667.

Klein A. M., Vaissiere B. E., Cane J. H., Steffan-Dewenter I., Cunningham S. A., Kremen C., Tscharntke T. (2007) Importance of pollinators in changing landscapes for world crops. Proceedings of the Royal Society B 274 303-313.

Konrad R., Ferry N., Gatehouse A. M. R., Babendreier D. (2008) Potential effects of oilseed rape expressing oryzacystatin-1 (OC-1) and of purified insecticidal proteins on larvae of the solitary bee Osmia bicornis. PLOS ONE 3(7): e2664.
Ladurner E., Bosch J., Kemp W. P., Maini S. (2005) Assessing delayed and acute toxicity of five formulated fungicides to Osmia lignaria Say and Apis mellifera. Apidologie 36: 449-460.

Ladurner E., Bosch J., Kemp W. P., Maini S. (2008) Foraging and Nesting Behavior of Osmia lignaria (Hymenoptera: Megachilidae) in the Presence of Fungicides: Cage Studies. Journal of Economic Entomology 101: 647-653. Maus C. (2008) Ecotoxicological profile of the insecticide spirotetramat. Bayer Crop Science Journal 61: 159-180.

Maus C. (2008) Ecotoxicological profile of the insecticide spirotetramat. Bayer Crop Science Journal 61: 159-180.

Peach M. L., Alston D. G., Tepedino V. J. (1995) Sublethal effects of carbaryl bran bait on nesting performance, parental investment, and offspring size and sex ratio of the alfalfa leafcutting bee (Hymenoptera: Megachilidae). Environmental Entomology 24: 34-39.

Peters D. S. (1977) Systematik und Zoogeographie der westpaleärktischen Arten von Osmia's str., Monosmia, und Orientosmia. Senckenbergiana Biologica 58: 287 346.

Radmacher S., Strohm E. (2010) Factors affecting offspring body size in the solitary bee Osmia bicornis (Hymenoptera, Megachilidae). Apidologie 41: 169-177.

Radmacher S., Strohm E. (2011) Effects of constant and fluctuating temperatures on the development of the solitary bee Osmia bicornis (Hymenoptera: Megachilidae). Apidologie 42: 711-720.

Rogers D., Williams G., Lam C., Fischer D., Hackenberg D. (2010) Movento ${ }^{\circledR}$, Citrus and Honey Bees. Results of a successful cooperative study. In: Proceedings of the American Bee Research Conference. Orlando-USA. 1415 January 2010. American Bee Journal: 506.

Rundlöf M., Andersson G. K. S., Bommarco R., Fries I., Hederström V., Herbertsson L., Jonsson O., Klatt B. K. Pedersen T. R., Yourstone J., Smith H. G. (2015) Seed coating with a neonicotinoid insecticide negatively affects wild bees. Nature 521 (7550): 77-80.

Sandrock C., Tanadini L. G., Pettis J. S., Biesmeijer J. C., Potts S. G., Neumann P. (2014) Sublethal neonicotinoid insecticide exposure reduces solitary bee reproductive success. Agricultural and Forest Entomology 16: 119 128. 


\section{J. APCL. SCL. VOL. 59 NO. 22015}

Schindler M., Diestelhorst O., Härtel S., Saure C., Schanowski A., Schwenninger H. R. (2013) Monitoring agricultural ecosystems by using wild bees as environmental indicators. Biorisk 8: 39-51.

Sgolastra F., Kemp W. P., Maini S., Bosch J. (2012) Duration of prepupal summer dormancy regulates synchronization of adult diapause with winter temperatures in bees of the genus Osmia. Journal of Insect Physiology 58: 924 933.

Sgolastra F., Kemp W. P., Buckner J. S., Pitts-Singer T. L., Maini S., Bosch J. (2011) The long summer: Pre-wintering temperatures affect metabolic expenditure and winter survival in a solitary bee. Journal of Insect Physiology 57: 1651-1659.

Statistica ver. 7. (2004) StatSoft Inc.
Tasei J. N., Carre S., Moscatelli B., Grondeau C. (1988) Recherche de la D.L. 50 de la deltamethrine (Decis) chez Megachile rotundata F. Abeille pollinistatrice de la luzerne (Medicago sativa L.) et des effets de doses infralethales sur les adultes et les larves. Apidologie 19 (3): 291-306.

Tesoriero D., Maccagnani B., Santi F., Celli G. (2003) Toxicity of three pesticides on larval instars of Osmia cornuta: preliminary results. Bulletin of Insectology 56: 169-171.

Vicens N., Bosch J. (2000) Nest site orientation and relocation of populations of the orchard pollinator Osmia cornuta (Hymenoptera: Megachilidae). Environmental Entomology 29: 69-75.

Wasielewski O., Wojciechowicz T., Giejdasz K., Krishnan N. (2013) Overwintering strategies in the red mason solitary bee-physiological correlates of midgut metabolic activity and turnover of nutrient reserves in females of Osmia bicornis. Apidologie 44: 642-656. 